\title{
The Psychosocial Problems Of Pulmonary Tuberculosis Patients Undergoing DOTS Therapy (Direct Observed Treatment Short Course Therapy) in Selected Areas of Jalandhar District, Punjab.
}

\author{
Veena Williams and Dr. Harbans Kaur \\ Scholars of Singhania University
}

Tuberculosis continues to be a major health problem in the world, particularly in the developing countries. The updated WHO report reveals that about 9.4 million new TB cases occurred in 2008 including 1.4 million cases among people living with HIV. The prevalence of the disease was about 11.1 million. There were about 1.3 million deaths from TB among HIV negative people and an additional 0.52 million TB deaths among HIV positive people. India is the highest TB burden country in the world, accounting for $21 \%$ of the global incidence and $2 / 3^{\text {rd }}$ of the cases in south-east Asia. In the year 2008, the incidence of tuberculosis was reported to be 1.9 million with prevalence of 2.186 million with mortality due to TB being $2,76,512$.

\section{Need for the study}

India is the highest TB burden country accounting for one fifth of the global incidence (Global annual incidence estimate is 9.1 million cases out of which it is estimated that 1.9 million cases are from India). India is $17^{\text {th }}$ among 22 High Burden Countries in term of TB incidence rate.

The Revised National TB control Programme (RNTCP), based on the internationally recommended Directly Observed Treatment Short-course (DOTS) strategy, was launched in 1997 expanded across the country in a phased manner with support from the World Bank and other development partners. Full nation wide coverage was achieved in March 2006 covering over a billion populations (1114 million) in 632 districts/ reporting units. In terms of treatment of patients, RNTCP is the largest and fastest expanding programme in the world. In 2005 alone, 1.29 million TB patients, in 2006, 1.39 million and in 2007, 1.48 million patients have been enrolled for treatment. In 2008, 1.51 million patients have already been placed on treatment.

WHO global tuberculosis report 2008, a district-wise survey of RNTCP 2008 (Revised National Tuberculosis Control Programme) also summarizes a total of 22864 cases, which are sputum smear positive cases found in the state of Punjab in India. But there is a high remarkable statistics of 37076 cases in Punjab which are presently under the DOTS therapy. A total of 3074 cases, which is 8.29 percent of total DOTS registered cases of Punjab (37076) are under DOTS therapy in Jalandhar district alone.

\section{Statement of the problem}

A Descriptive Study To Assess The Psychosocial Problems Of Pulmonary Tuberculosis Patients Undergoing DOTS Therapy (Direct Observed Treatment Short Course Therapy) in Selected Areas of Jalandhar District, Punjab.

\section{Objectives of the study}

- To assess the psychological problems of pulmonary tuberculosis patients undergoing DOTS therapy.

- To assess the sociological problems of pulmonary tuberculosis patients undergoing DOTS therapy.

- To analyze the relationship between psychological and sociological problems among pulmonary tuberculosis patients.

- To analyze the relationship of psychological problems of pulmonary tuberculosis patients with selected sociodemographic variables.

- To analyze the relationship of sociological problems of pulmonary tuberculosis patients with selected sociodemographic variables.

- To submit the analyzed data to the concerned health authority of district Jalandhar, Punjab.

\section{Assumption}

- Researcher assumes that pulmonary tuberculosis patients undergoing DOTS therapy face the psychosocial problems. This fact is supported by the studies conducted on pulmonary tuberculosis which revealed that there is a need to make research on psychosocial problems of tuberculosis patients. 


\section{Conceptual Framework}

In the present study, conceptual framework is developed on the basis of Betty Neuman's "The Neuman Systems MODEL"(1985).Through this framework, the researcher tends to analyse the psychological and sociological problems of pulmonary tuberculosis patients undergoing DOTS therapy.

The ideal to achieve optimal system stability, Neuman agrees with Heslin (1986) that when a system achieves stability, a revitalization occurs. As an open system, the client system has a prospenity to seek or maintain a balance among the various factors, both within and outside the system, that seek to disrupt it(Neuman,2002c). Neuman labels these forces as stressors and views them as capable of having either positive or negative effects .Reactions to the stressors may be possible(not yet occurring) or actual, with identifiable responses and symptoms

\section{Material and Methods}

\section{Research Methodology}

The study was conducted on pulmonary tuberculosis patients undergoing DOTS therapy in district Jalandhar , Punjab

\section{Research Approach/Design}

A non- experimental descriptive research approach and design was used.

\section{Selection of population and setting}

The study was conducted in selected areas of district Jalandhar, Punjab in year 2010.The study sample for analyzing psychosocial problems of pulmonary tuberculosis patients undergoing DOTS therapy were 500 .

Tool: Tool consist of two parts.

Part A: Socio- demographic variable according to socio demographic variables respondents were distributed into various categories according to age, gender, religion, education, occupation, marital status, divorce occurred .

Part B : Structured check list to measure psychological and sociological problems of pulmonary tuberculosis patients undergoing DOTS therapy. It consist of 20 items to which respondents were expected to answer Yes/No(any other specific answer).Each correct response carried one as score and wrong carried zero score.The total maximum score was 20.

\section{Reliability of tool:}

Reliability was computed by split-half reliability method using spearman's brown prophecy formula. Reliability of the check list to assess psychological problems was 0.94 and reliability of the check list to assess sociological problems was 0.99

\section{Data collection}

Data was collected from 14 designated microscopic centers of selected RNTCP centers of Civil Hospital, Jalandhar, Punjab after getting formal approval from district TB officer, during the months of March to May 2010.

\section{Data analysis}

Data obtained was tabulated and analyzed pertaining to specific objectives.

i. To assess the psychological problems of pulmonary tuberculosis patients undergoing DOTS therapy.

ii. To assess the sociological problems of pulmonary tuberculosis patients undergoing DOTS therapy.

\section{Objectives}

Objective 1:- To assess the psychological problems of pulmonary tuberculosis patients undergoing DOTS therapy. Most of the patients having pulmonary tuberculosis undergoing DOTS therapy shown maximum results in category of psychological problems related to sadness due to disease (76.2\%) and minimum results related to feeling of worthlessness (32\%).Among psychological problems, pulmonary tuberculosis patients undergoing DOTS therapy showed maximum results in category of sadness due to disease $(76.2 \%)$,followed by feeling emotionally disturbed(73.2\%), followed by patients loosing temper while dealing with others $(53.2 \%)$ and in presence of sleep disturbance(51.2\%).

Objective 2:- To assess the sociological problems of pulmonary tuberculosis patients undergoing DOTS therapy. Among sociological problems, patients with pulmonary tuberculosis undergoing DOTS therapy showed maximum results in category of finding difficulty to continue job (41.2\%), followed by preferring stay alone (39.6\%), followed by not finding co-operation from colleagues at work place( $25.2 \%)$,followed by feeling of isolation by friends and relatives(24.8\%)and loss of job due to disease(23.6\%). 9.82)and least in married (9.63) which was statistically significant at $\mathrm{p}<0.05$. 
Objective 3:- According to overall psychological and sociological problem score of subjects shows that pulmonary tuberculosis patients experience more sociological problems than psychological problems.

Table 1 : Overall psychological and sociological problem score of the subjects

$$
\mathbf{N}=\mathbf{5 0 0}
$$

\begin{tabular}{lccc}
\hline \multicolumn{1}{c}{ Problems } & n & Mean & SD \\
& & & \\
\hline Psychological problem & 500 & 12.84 & 4.04 \\
Sociological problem & 500 & 16.63 & 2.62 \\
\hline & & Max score $=20$ & \\
& & Min score=0
\end{tabular}

Table 1 shows that overall psychological and sociological problem score of subjects . The mean sociological problem score of subject is more (16.63)than the mean psychological problem score(12.84).

Hence, it can be said that pulmonary tuberculosis patients experience more Sociological problems than Psychological problems.

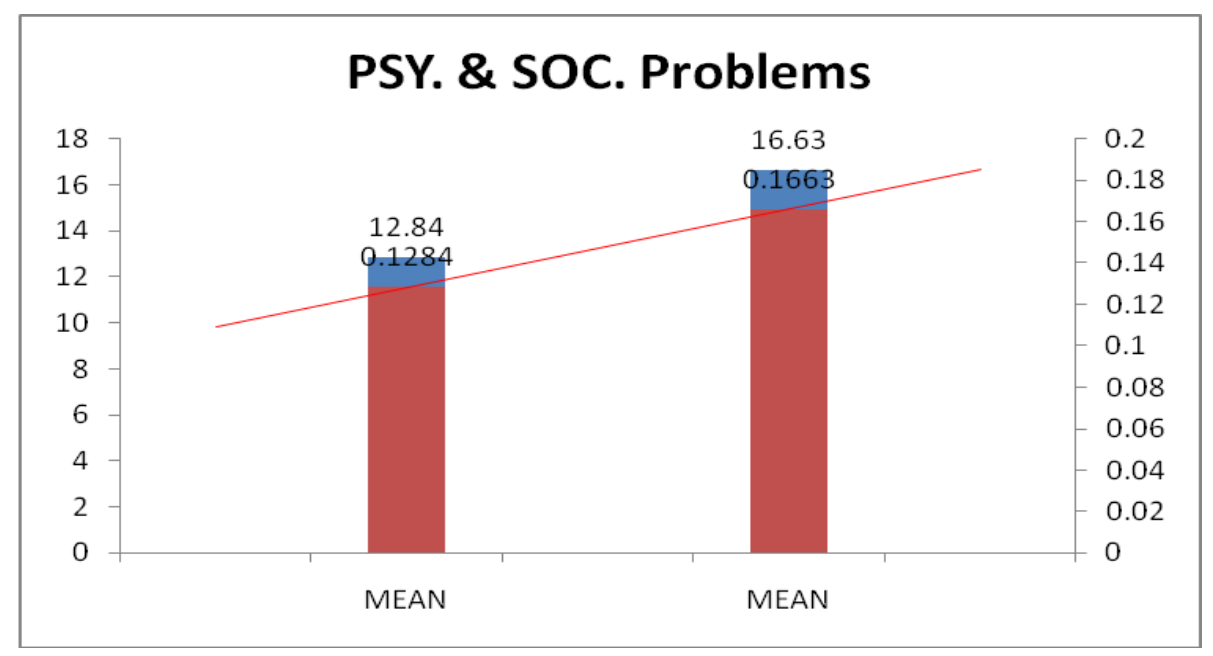

Fig1 : Overall psychological and sociological problem score of the subjects

Objective 5: To analyze the relationship of sociological problems of pulmonary tuberculosis patients with selected socio-demographic variables.

Table 2 : Monthly family income and Sociological problems score among subjects

\begin{tabular}{|c|c|c|c|c|c|}
\hline Monthly Family Income (in Rs.) & Mean & $\mathbf{N}$ & SD & df & ANOVA test \\
\hline$<5000$ & 9.76 & 357 & 2.0 & \multirow{4}{*}{3,496} & \multirow{4}{*}{$\mathrm{F}=2.313$} \\
\hline $5001-10000$ & 9.58 & 131 & 1.59 & & \\
\hline $10001-15000$ & 9.50 & 10 & 1.77 & & \\
\hline$>15000$ & 13.0 & 7 & 2.82 & & \\
\hline
\end{tabular}

Table 2 shows that respondents having monthly family income more than Rs 15000 of family have the highest mean sociological problem score (13), followed by respondents with family income less than Rs 5000 (9.76),followed by respondents with family income of Rs 5001-10000(9.58),followed by respondents with family income Rs10001-15000(9.5). The difference in the mean is statistically significant at $\mathrm{P}<0.05$.

Thus it can be said that monthly family income leads to more sociological problems among tuberculosis patients. 


\section{Monthly family income.}

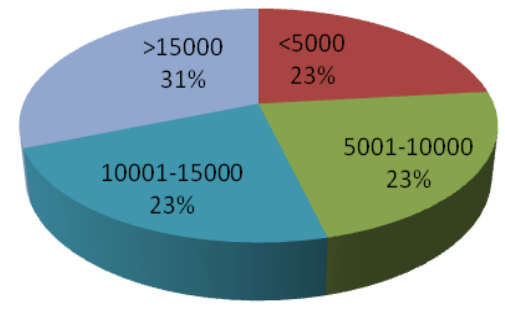

Fig 2 : Monthly Family Income and Sociological Problem Score among Subjects.

Table 3 : Family history of TB and Sociological problems score among subjects

\begin{tabular}{|l|c|c|c|c|}
\hline Family History of TB & $\mathbf{N}$ & Mean & SD & ' $\mathbf{t}$ '- test value \\
\cline { 1 - 4 } Present & 39 & 10.41 & 2.83 & \multirow{2}{*}{$2.336^{*}$} \\
\hline Absent & 461 & 9.67 & 1.80 & \\
\hline *statistically significant & & & & $\mathrm{p}<0.05$ \\
\hline
\end{tabular}

Table 3 illustrates that respondents with family history of TB have the highest mean sociological problem score (10.41), followed by respondents have no history of TB (9.67), the difference in the mean is statistically significant at $\mathrm{p}<0.05$

Thus it can be said that family history of TB leads to more sociological problems among tuberculosis patients.

\section{Family Hist. of T.B}

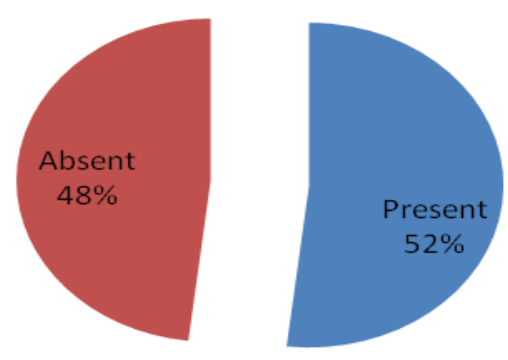

Fig 3 : Family History of TB and Sociological Problem Score among Subjects.

Table 4 : Awareness about TB and Sociological problems score among subjects

\begin{tabular}{|l|c|c|c|c|}
\hline Awareness about TB & N & Mean & SD & 't' - value \\
\hline Present & 239 & 9.99 & 1.93 & \multirow{2}{*}{$2.99 *$} \\
\hline Absent & 259 & 9.48 & 1.86 & \\
\hline
\end{tabular}

*statistically significant

$$
\mathrm{p}<0.05
$$

Table 4 depicts that respondents having awareness of TB have the highest mean sociological problem score (9.99), followed by respondents have no awareness of TB (9.48), the difference in mean is statistically significant at $\mathrm{p}<0.05$

Thus it can be said that the awareness of TB leads to more sociological problems among tuberculosis patients. 


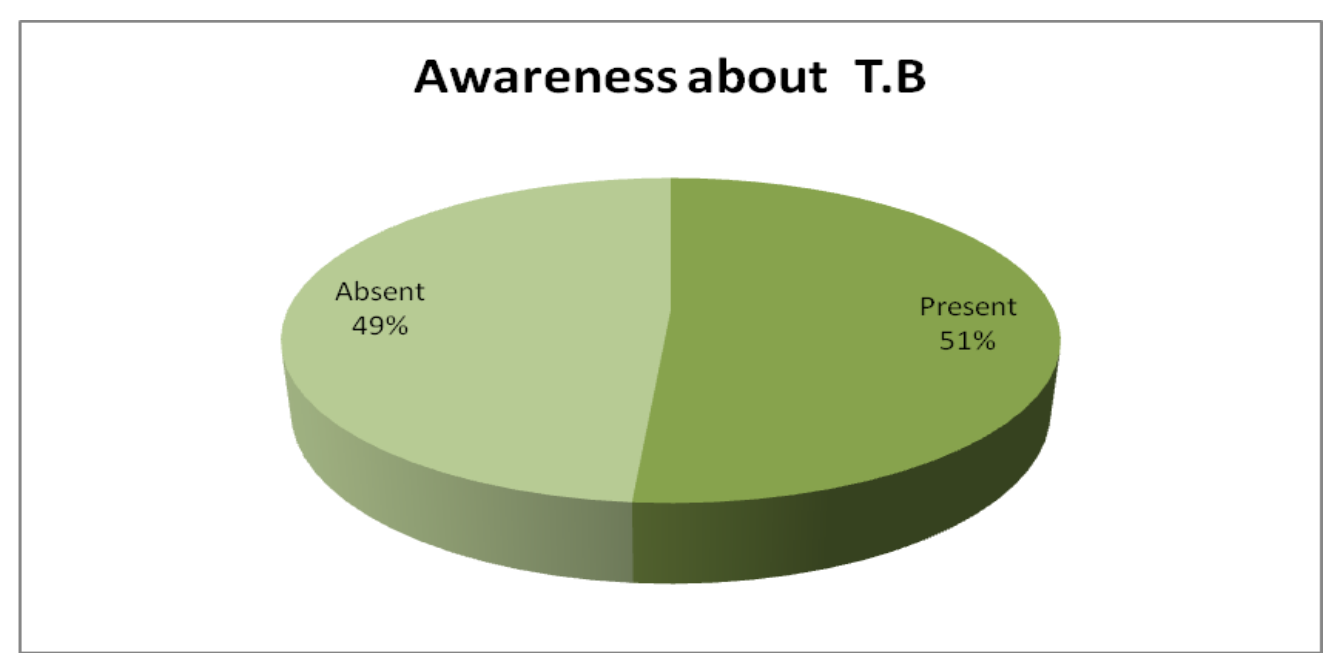

Fig 4 : Awareness about TB and Sociological Problem Score among subjects.

\section{Implications of the study}

- This study will help to incorporate the dimensions of psychosocial aspect of pulmonary tuberculosis patients in rendering comprehensive care to tuberculosis patients.

- This study will help in carrying out interventions at community level which will help the pulmonary tuberculosis patients to cope-up with the psycho-social problems hence will reduce the incidence of nonadherence to treatment.

\section{In Nursing Education}

The students should be taught about the DOTS therapy in detail and they should be provided information about DOTS therapy on the basis of various research findings. They should also be taught about the role that significant relatives play in the treatment and prevention of pulmonary tuberculosis. They should teach relatives about the treatment .This will give the students a better understanding to learn and apply their knowledge regarding educating the relatives and community about pulmonary tuberculosis and DOTS therapy.

\section{In Nursing Research}

The information contained in the present study can be valuable source of data for the future researchers. It can help them in conducting research with large sample size in different settings.

\section{In Nursing Practice}

The nurse should be able to provide the preventive, promotive and curative care to patients and their families in hospitals and in community .The nurse while caring for the patients should also include the family members in the care of the patient so that they can also gain skills in caring for their patients at the home. Health education must be provided to the patients as well as their family members about the illness of the patient and the treatment that the patient is getting so that the family can make the patients adhere to the treatment plan i.e. DOTS therapy.

\section{In Community Health Nursing}

The present study focuses that patients utilizing health services are compliant to the treatment regimen, but the same cannot be inferred for those in community, who are not utilizing the services. Therefore the community health nurse can put more emphasis on the carring out surveys to find out the patients suffering from pulmonary tuberculosis those who are not being treated in hospitals. The knowledge of their family members can be checked and need based information can be provided so that they get motivated to get their patient treated in the hospital. Those who are already getting treatment can be educated regarding treatment compliance so that relapses can be prevented and moreover psychological problems can be reduced.

\section{Recommendations}

1. The study can be replicated on a large sample to validate and generalize findings.

2. A comparative study can be conducted on pulmonary tuberculosis patients undergoing DOTS therapy in outpatient departments of the hospitals. 
3. A comparative study can be conducted on pulmonary tuberculosis patients undergoing DOTS therapy in rural and urban areas.

\section{References:}

[1] Behra D.Expanding DOTS- New strategies for TB control. Indian Journal of Tuberculosis. 2010.57(2); 63-66

[2] Bhatia M.S, Bhasin S.K, Dubey K.K, Psychological dysfunction in Tuberculosis patients, 2000.54; $171-173$.

[3] Uplekar M, Juvekar S, Morankal S, Rangan S, Tuberculosis patients and practitioners in private clinics in India.International journal of tuberculosis lung disease.1998.2(4); 324-329.

[4] Chadha V.K, Tuberculosis epidemiology in India.. Indian journal of tuberculosis .2005.9(10); 1072-1082.

[5] Aggarwal N, Ashutosh, Health related quality of life. A neglected aspect of pulmonary tuberculosis. Department of pulmonary medicine postgraduate institute of medical education and research Chandigarh.web publications. 2010.27; 1-3.

[6] Navneet Singh, Gupta Dheeraj, Revised National Tuberculosis Control Programme in India: current status \& challenges. Revised national tuberculosis control programme in india. 2005.22; 107-111.

[7] Arora V.K, Singla Neeta, Gupta Ranish, Community mediated Domiciliary DOTS executive, Indian Journal of Tuberculosis, 2003.50; 143.

[8] Macq. Jean, Solis Alejandre et al, Trackling tuberculosis patients internalized social stigma through patient centred care: An International study in rural Nicaragua, 2005.

[9] Brodie Daniel, Scheunger W-Niel. The diagnosis of tuberculosis clinics in chest medicine 2005.26; $247-271$.

[10] Khan shabad, Dhingra V.K. A sociological study on stigma among TB patients in Delhi. Indian journal of tuberculosis. 2010.57; 12-18. 